\title{
Amino acids profile in girls with Turner syndrome during growth hormone therapy
}

\author{
Jolanta Bugajska', Joanna Berska', Małgorzata Wójcik², Jerzy B. Starzyk², Krystyna Sztefko' \\ ${ }^{1}$ Department of Clinical Biochemistry, Institute of Paediatrics, Jagiellonian University Medical College, Krakow, Poland \\ ${ }^{2}$ Department of Paediatric and Adolescent Endocrinology, Institute of Paediatrics, Jagiellonian University, Medical College, Krakow, Poland
}

\begin{abstract}
Introduction: The influence of growth hormone $(\mathrm{GH})$ treatment on amino acids (AAs) profile in patients with Turner syndrome (TS) was investigated.

Material and methods: The study group included girls with TS: treated with $\mathrm{GH}(\mathrm{GH}+)$ and girls with no $\mathrm{GH}$ treatment $(\mathrm{GH}-)$. The control group consisted of healthy girls. Free plasma AAs were measured by the LC/MS/MS.

Results: The plasma concentrations of glutamine, threonine were significantly higher in group $\mathrm{GH}+$ than in group $\mathrm{GH}-(\mathrm{p}<0.05)$. In group $\mathrm{GH}-$ the values of glutamine, alanine, isoleucine, glutamic acid were significantly different than in the control ( $p<0.05-\mathrm{p}<0.008)$. Conclusion: AAs profile in girls with TS might be characteristic for the disease but also depends on GH treatment. (Endokrynol Pol 2021; 72 (1): 51-52)
\end{abstract}

Key words: amino acids, growth hormone, Turner syndrome

\section{Introduction}

Turner syndrome (TS) is the most common chromosomal disorder causing short stature in females. Patients with TS, although they do not have growth hormone deficiency, are commonly treated with recombinant human growth hormone $(\mathrm{GH})$ to improve their final height [1]. There are conflicting data in literature regarding the impact of $\mathrm{GH}$ replacement therapy on changes in plasma amino acids (AAs) concentration [2-4] and there are no published studies investigating AAs levels during growth hormone therapy in girls with TS. It is not known if GH therapy, which is important for proper protein anabolism, causes changes in free AAs levels in girls with TS. Therefore, the aim of this study was to assess the influence of GH treatment on amino acids profile in patients with TS.

\section{Material and methods}

Thirty-six girls with Turner syndrome [ 17 with $X$ chromosome monosomy $(45, X), 6$ with abnormal $X$ chromosome and 13 with mosaicism] were selected for the study group. 28 of them were receiving growth hormone therapy (group $\mathrm{GH}+$ ) and 8 of them were not receiving growth hormone therapy (group GH-). The control group consisted of 18 girls with normal stature and no metabolic diseases.

Free plasma AAs were measured by the LC/MS/MS (Agilent Technologies, Jasem). Glucose, total cholesterol and triglycerides concentrations were measured by dry chemistry analyser (Vitros 4600, Ortho Clinical Diagnostics Inc., Rochester, NY, USA). Insulin-like growth factor 1 (IGF1) concentrations were measured in serum samples with radioimmunoassay method (DIAsource SM-C-RIA-CT Kit, Belgium).
The questionnaire and methodology for this study was approved by the Jagiellonian University Bioethics Committee (Protocol No.122.6120.35.2016).

\section{Results}

Fasting serum concentrations of glucose, total cholesterol, triglycerides and amino acids: aspartic acid, glycine, taurine, citrulline, arginine, proline, tyrosine, valine, leucine levels in group $\mathrm{GH}+$, group $\mathrm{GH}-$ and in the control did not differ significantly.

The statistically significant differences in the mean values of IGF1, glutamic acid, serine, asparagine, glutamine, histidine, threonine, alanine, methionine, isoleucine, phenylalanine, tryptophan, ornithine and lysine between group $\mathrm{GH}+$, group $\mathrm{GH}-$ and the control are summarized in Table 1.

\section{Discussion}

Treatment with GH has been established to be effective for increasing final stature in patients with TS. The anabolic action of GH may involve redistribution of nitrogen from ureagenesis to the extrahepatic anabolic process, together with stimulation of AAs uptake and protein synthesis in the muscles [5]. Höybye et al. [4] demonstrated higher levels of glutamic acid and aspartic acid in adults GH deficiency patients than in the control, but only for glutamic acid this difference was significant. GH treatment tended to decrease the levels of these AAs towards the levels in the 
healthy subjects [4]. Similar results have been obtained in the present study, levels of glutamic acid and aspartic acid were decreased during GH therapy, but these differences for aspartic acid were not statistically significant. Fernholm et al. [2] did not find significant changes in plasma AAs levels either in males or females after 12 months of GH replacement therapy. While Lundeberg et al. [3] showed in healthy male volunteers a higher concentration of glutamine, alanine and lower levels of valine, leucine and histidine in plasma in the growth hormone treated group as compared with the initial values. In the previous study [6] we found higher concentrations of mean values of glutamine and threonine in TS patients with GH therapy than in TS patients without GH therapy. That results have been confirmed now. Xu et al.[7] demonstrated higher serum levels of phenylalanine and tyrosine and lower serum levels of serine, lysine, and glutamine in the short stature children compared with the healthy children. The lower levels of lysine and glutamine are the metabolic characterization of the affected growth axes and stress state of short stature children, respectively [7]. We observed, that the concentrations of glutamine in girls with TS normalised upon GH-treatment. Most studies demonstrated that growth hormone and glutamine in combination exerted synergistic effects in the treatment of various diseases e.g. activate the proliferation of crypt cells and intestinal stem cells and enhance mucosal growth [8]. It is known that oral administration of a specifically formulated combination of AAs can increase serum human growth hormone level [9].

\section{Conclusions}

Amino acids profile in girls with Turner syndrome might be characteristic for the disease but also depends on $\mathrm{GH}$ treatment. The combined use of GH treatment and oral administration of amino acids may improve metabolism in girls with Turner syndrome.

\section{References}

1. Ahn JM, Suh JH, Kwon AhR, et al. Final Adult Height after Growth Hormone Treatment in Patients with Turner Syndrome. Horm Res Paediatr. 2019; 91(6): 373-379, doi: 10.1159/000500780, indexed in Pubmed: 31480041.

2. Fernholm R, Thoren M, Hoybye C, et al. Amino acid profiles in adults with growth hormone $(\mathrm{GH})$ deficiency before and during $\mathrm{GH}$ replacement therapy. Growth Horm IGF Res. 2009; 19(3): 206-211, doi: 10.1016/j. ghir.2008.09.001, indexed in Pubmed: 18990596.

3. Lundeberg S, Belfrage M, Wernerman J, et al. Growth hormone improves muscle protein metabolism and whole body nitrogen economy in man during a hyponitrogenous diet. Metabolism. 1991; 40(3): 315-322, doi: 10.1016/0026-0495(91)90116-e, indexed in Pubmed: 2000045.

4. Höybye C, Wahlström E, Tollet-Egnell P, et al. Metabolomics: a tool for the diagnosis of GH deficiency and for monitoring GH replacement? Endocr Connect. 2014; 3(4): 200-206, doi: 10.1530/EC-14-0098, indexed in Pubmed: 25312907.

5. Salomon F, Cuneo R, Sönksen PH. Growth hormone and protein metabolism. Horm Res. 1991; 36 Suppl 1: 41-43, doi: 10.1159/000182187, indexed in Pubmed: 1806483.

6. Bugajska J, Berska J, Wójcik M, et al. Metabolic Fingerprint of Turner Syndrome. J Clin Med. 2020; 9(3), doi: 10.3390/jcm9030664, indexed in Pubmed: 32131408.

7. $\mathrm{Xu} \mathrm{R}, \mathrm{Zhu} \mathrm{H}$, Zhang C, et al. Metabolomic analysis reveals metabolic characteristics of children with short stature caused by growth hormone deficiency. Clin Sci (Lond). 2019; 133(6): 777-788, doi: 10.1042/CS20181005, indexed in Pubmed: 30867230.

8. Chen Y, Tsai YH, Tseng BJ, et al. Influence of Growth Hormone and Glutamine on Intestinal Stem Cells: A Narrative Review. Nutrients. 2019; 11(8), doi: 10.3390/nu11081941, indexed in Pubmed: 31426533.

9. Tam CS, Johnson WD, Rood J, et al. Increased Human Growth Hormone After Oral Consumption of an Amino Acid Supplement: Results of a Randomized, Placebo-Controlled, Double-Blind, Crossover Study in Healthy Subjects. Am J Ther. 2020; 27(4): e333-e337, doi: 10.1097/MJT.0000000000000893, indexed in Pubmed: 30893070.

Table 1. Clinical characteristics and fasting serum concentrations of IGF1, glucose, total cholesterol, triglycerides and fasting plasma concentrations of amino acids in the control group and in the study group

\begin{tabular}{|c|c|c|c|c|c|}
\hline \multirow{2}{*}{ Parameter } & \multicolumn{4}{|c|}{ Turner syndrome } & \multirow{2}{*}{$\begin{array}{l}\text { Control group } \\
\quad(n=18)\end{array}$} \\
\hline & \multicolumn{2}{|c|}{$\mathrm{GH}+(\mathrm{n}=28)$} & \multicolumn{2}{|c|}{$\mathrm{GH}-(\mathrm{n}=8)$} & \\
\hline Age [years] & $12.5 \pm 0.7$ & & $9.2 \pm 1.3$ & & $14.7 \pm 0.9$ \\
\hline Body mass index [SDS] & $0.25 \pm 0.17$ & & $0.27 \pm 0.32$ & & $0.24 \pm 0.21$ \\
\hline IGF1 [ng/mL] & $589.6 \pm 313.7$ & $p=0.023^{b}$ & $229.2 \pm 87.1$ & & $395.1 \pm 119.0$ \\
\hline \multicolumn{6}{|l|}{ Amino acids $[\mu \mathrm{mol} / \mathrm{L}]$} \\
\hline Isoleucine & $72.1 \pm 3.9$ & & $61.1 \pm 8.3$ & $p=0.008^{a}$ & $79.9 \pm 11.6$ \\
\hline Threonine & $132.8 \pm 32.1$ & $\begin{array}{c}p<0.05^{b} \\
p=0.0004^{a}\end{array}$ & $92.9 \pm 16.0$ & $p=0.0002^{a}$ & $171.1 \pm 39.5$ \\
\hline Methionine & $20.7 \pm 3.9$ & $p=0.0006^{a}$ & $18.3 \pm 1.4$ & $p=0.0007^{a}$ & $25.9 \pm 4.1$ \\
\hline Phenylalanine & $53.7 \pm 8.2$ & $p=0.0007^{a}$ & $54.9 \pm 7.3$ & $p<0.05^{a}$ & $64.6 \pm 8.4$ \\
\hline Lysine & $180.1 \pm 29.3$ & $p=0.04^{a}$ & $168.2 \pm 15.4$ & $p=0.03^{a}$ & $203.5 \pm 26.1$ \\
\hline Tryptophan & $52.4(46.1-61.1)$ & $p=0.003^{a}$ & $59.1(55.7-64.6)$ & & $65.4(62.1-73.1)$ \\
\hline Histidine & $77.0 \pm 9.5$ & $p=0.002^{a}$ & $72.9 \pm 7.2$ & $p=0.005^{a}$ & $89.8 \pm 12.1$ \\
\hline Glutamic acid & $23.5(19.3-41.7)$ & & $37.1(30.3-50.9)$ & $p=0.03^{a}$ & $18.3(13.8-34.0)$ \\
\hline Serine & $112.9 \pm 21.9$ & $p=0.005^{a}$ & $106.8 \pm 22.2$ & $p=0.03^{a}$ & $138.6 \pm 25.0$ \\
\hline Asparagine & $41.4 \pm 7.7$ & $p=0.03^{a}$ & $38.2 \pm 5.4$ & $p=0.03^{a}$ & $48.6 \pm 8.6$ \\
\hline Glutamine & $640.8 \pm 83.5$ & $p=0.05^{b}$ & $540.4 \pm 89.2$ & $p=0.03^{a}$ & $661.4 \pm 72.1$ \\
\hline Alanine & $356.4 \pm 92.7$ & & $287.0 \pm 69.7$ & $\mathrm{p}<0.05^{\mathrm{a}}$ & $379.5 \pm 65.4$ \\
\hline Ornithine & $42.8 \pm 9.1$ & & $39.8 \pm 9.3$ & $p=0.02^{a}$ & $52.9 \pm 9.4$ \\
\hline
\end{tabular}

aas compared to control; bas compared to $\mathrm{GH}$ - group; to evaluate the distribution of continuous variables in terms of its compliance with the normal distribution, the Shapiro-Wilk test was employed. Comparison between groups was performed by using one-way ANOVA test with Tukey unequal N HSD post-hoc test. A p value less than 0.05 was considered statistically significant. Statistica software version 10 (StatSoft) was used to perform statistical analysis; Mean value \pm SD or Median (interquartile range) 